\title{
Effect of Partnership Based Program with Primary Caregivers of Children on Stoma Care
}

\author{
Nagwa I. Rashed ${ }^{1}$, Maha I. Khalifa ${ }^{2}$, Nagwa A. Zein El Dein ${ }^{3}$, Taghrees \\ K. Omar ${ }^{4}$ \\ ${ }^{1}$ Assistant lecturer of Pediatric Nursing, ${ }^{2}$ Professor of Pediatric Nursing, ${ }^{3}$ Professor of \\ Pediatric Nursing, ${ }^{4}$ Emeritus professor of Pediatric Nursing, Faculty of Nursing, Menofia \\ University
}

\begin{abstract}
Background Primary caregivers are those who are concerned with the client care in the hospital and home. Most of the caregivers are not able to provide stoma care with quality to their children. Hence, caregivers need to be provided with ongoing education and support through partnership commencing from preoperative teaching to discharge from the hospital and home care .The purpose of this study was to assess the effect of partnership based program with primary caregivers of children on stoma care. The design of this study was quasi-experimental design. The study was conducted in the Pediatric surgical department and outpatient clinics at both Menoufia University Hospital and Benha Specialized Pediatric Hospital. The study sample was composed of 60 children and their caregivers were selected from previously mentioned settings (30 studies and 30 control group). Five instruments were used in the study. They were Social Characteristics Structured Questionnaire, Structured Interview Questionnaire, Stoma Care Checklist, Stoma Assessment Sheet and Quality of Partnership Likert Scale. The results of this study showed that caregivers had higher mean score of knowledge posttest in the study group compared to control group $(61.30 \pm 5.2$ Vs. $14.63 \pm 5.7$ respectively) In addition, children had better stoma clinical condition in the study group compared to control group as well as caregivers higher levels of partnership quality on post and follow-up intervention compared to pre intervention (96.7\%, $100.0 \%$ vs. 6.7\%, respectively).. Conclusion: implementation of partnership based program increased caregivers' knowledge and practices regarding care of children with stoma. Therefore, it was recommended that Partnership based program for stoma care should be urgently planned and implemented to improve caregivers' knowledge and practice as well as improve children health status.
\end{abstract}

Key words: Partnership, Primary caregivers, Stoma care.

\section{Introduction}

Congenital anomalies (CAs) are a worldwide problem. They are important causes of childhood deaths and disability. According to World Health Organization (2016), three million newborn are born yearly with major CAs, constituting about $3 \%$ of all newborns. In Egypt the prevalence of congenital and genetic disorders in infants and young children ranges from $2.8 \%$ in urban areas to $8.4 \%$ in rural areas (Abdou et al., 2019).

Stoma is considered a surgical intervention with the function of facilitating the communication between internal organ and the external environment. It can be made in both the small intestine (ileostomy) and the large intestine (colostomy). A surgical incision is done to connect the small or large intestine to the abdominal wall to allow intestinal emptying (Maia \& Assis, 2019). There are many further conditions which require the stoma surgical incision in order to help children to survive. These conditions are malformation of the intestines, HD, ARM, Inflammatory bowel disease, Crohn's disease, necrotizing entrocolities (NEC), Trauma and Colon Cancer (Massenga et al., 2019) Furthermore, children with stoma face a number of psychosocial problems such as fear, embarrassment, distress and negative body image. They rely on caregivers to effectively resolve these problems and suggest stoma care products that will relieve discomfort and 
anxiety (Cengiz \& Bahar, 2017). Above all, most of the caregivers are not able to provide care to children with colostomy so, they need to prepared with the relevant knowledge and practice that enabling them to identify the cause of these problems, provide care and reassurance to children with stomas who may have misconceptions of stoma formation and its care (Sun et al., 2018).

Caregivers need to have knowledge of care, cure \& prevention to improve their quality of care also, helps to change their attitude regarding colostomy care (Kadam\& Shinde, 2017). This knowledge must be based on parental needs in order to develop an effective nurse-parent partnership that will help to minimize parental stress. Nurses have a central role in the care of sick child; they can alleviate parental stress by establishing caring relationships, sharing knowledge and information, paying attention to support parents psychologically and physically, involving parents in decision making and empowering them in their child's care (Lam et al., 2017).

The American Academy of Pediatrics (AAP) policies identified that partnership in care can improve outcomes for children, families and health care providers (AAP, 2018). UNICEF, (2017) mentioned that $40 \%$ of children's' deaths could be prevented by improving the family and community care through increasing the knowledge, support and family collaboration.

Partnership involves parents, families and practitioners working together to benefit children. Each recognizes respects and values what the other does and says. It involves responsibility on both sides. Partnership- in care requires nurses to shift from a position of care prescriber to one of collaborator, working in partnership with parents, the child and wider family (Smith et al., 2018). Developing effective parent-professional partnerships has mutual benefits for parents such as enhanced parent psychosocial adjustment, decreased parenting stress, increased family involvement and adjustment to the child's health condition (Kuhlthau et al., 2018). Partnership also has profound benefits to children, including decrease the length of time, placed in out-of-home care and facilitated his/her reintegration into the family unit (Alfandari, 2017). Therefore, this study aimed to assess the effect of partnership based program with primary caregivers of children on stoma care.

\section{Purpose}

The purpose of this study is to assess the effect of partnership based program with primary caregivers of children on stoma care

\section{Research Hypothesis:}

1. Primary caregivers who received partnership based program had high knowledge about stoma care than primary caregivers who received only routine hospital care.

2. Primary caregivers who received partnership based program would demonstrated better stoma care than primary caregivers who received only routine hospital care.

3. Children had better clinical condition of their stoma than those who received only routine hospital care .

\section{Methods}

Research Design: A quasi-experimental design (Study and Control group) was utilized for this study

Setting: The study was conducted in the Pediatric Surgical Department and Outpatients of Pediatric Surgical Clinics at both Menoufia University Hospital and Benha Specialized Pediatric Hospital.

Subjects: sixty children and their primary caregiver (58 mothers and 2 fathers) were obtained from the above mentioned settings. A simple random sample was used to assign them into study and control group. Each group contained 30 children and their primary care givers. a. Study group: involved thirty children and their primary care 
givers (20 children were selected from Benha Specialized Pediatric hospital and 10 children from Menoufia University Hospital) they received partnership based program; 3 session for three consecutive days along with routine hospital care. Meanwhile, the control group: involved 30 children and their primary care givers (20 children were selected from Benha Specialized Pediatric hospital and 10 children from Menoufia University Hospital) they only received routine hospital care.

\section{Inclusion Criteria :}

All primary caregivers of children who were scheduled for temporary or permanent stoma surgeries were invited to participate in the study regardless of the age of their children or caregivers level of education.

\section{Exclusion Criteria}

All primary caregivers who had any disability (cognitive or others) which might block communication were excluded.

\section{Instrument:}

Five instruments were utilized for data collection:

\section{Instrument one: Social Characteristics Structured Questionnaire:}

It is Structured Interview Questionnaire. It was developed by the researcher in simple Arabic language based on review of related literature. It was divided into three parts:

1. Part one: Characteristic of children. It included questions about age, sex and birth order.

2. Part two: Demographic characteristics of primary caregivers. It included questions about age, education, occupation, residency and telephone number.

3. Part three: Medical history of the child. It included question about diagnosis, previous hospitalization, causes of hospital admission, site and type of stoma either permanent or temporary.

Instrument two: $\quad$ Structured

\section{Interviewing Questionnaire: -}

It is a multiple choice questions that was adopted from Mohey El Din (2014) then modified by the researcher after a review of literature used to assess knowledge of primary caregivers regarding the stoma, it was divided into four parts $(a=.984)$

1. Part one: Knowledge about stoma, it included 14 items about definition, causes, types, characteristics of healthy stoma and its complications, etc.

2. Part two: knowledge about stoma care, it contained 6 items about stoma care, care of stoma during bathing, method of skin care, etc.

3. Part three: knowledge about proper nutrition, it included 8 item about nutrition after stoma surgery, foods recommended after operation, foods that causes distention or bad odder, etc.

4. Part four: knowledge about follow-up and home care, it included importance of follow up and places that provide follow up visits.

The Total Scoring System of Caregiver's Knowledge:

\begin{tabular}{|l|c|}
\hline Level of knowledge & Score \\
\hline Poor & $<50 \%$ \\
\hline Fair & $50-75 \%$ \\
\hline Good & $>75 \%$ \\
\hline \\
Instrument three: & Stoma Care \\
\hline
\end{tabular}
Checklist:

It was adopted from Ayed (2014) and modified by the researcher to assess the primary caregiver's practices related to stoma care. It was divided into three phases of stoma care $(a=.973)$.

1. Phase one: Preparatory phase It included 4 steps such as: Prepare the needed equipment, Place child on his/her back, Wash hands and place waterproof sheet under the child.

2. Phase two: Performance phase (Applying the pouch): It included 12 steps they were wear gloves, support the skin and gently pull the barrier and 
bag away from the child, remove the used pouch and discard it, observe the stoma and the skin around it, wash the stoma with clean water, wash the skin around the stoma with warm water and mild soap then rinse the area and dry it, etc.

3. Phase three: Follow-up phase: after the procedure it contained 3 steps they were remove waterproof sheet, return and clean the equipment then wash hands.

Total Scoring System of Caregivers Practice about Stoma -

\begin{tabular}{|l|c|}
\hline Scoring items & Score \\
\hline Not Done & $<50 \%$ \\
\hline Done & $>50 \%$ \\
\hline
\end{tabular}

Instrument four: Stoma Infection Assessment Sheet:

It is an observational checklist to assess stoma general condition and presence of infection. It was developed by the researcher after a review of literature related to Abo Alizm (2010).it include : Bacteriological tests: it includes lab studies for bacteriological investigation.

\begin{tabular}{|l|c|}
\hline $\begin{array}{l}\text { Stoma Swab ( Culture Sensitivity } \\
\text { Test }\end{array}$ & \\
\hline Negative & $-\mathrm{ve}$ \\
\hline Positive & $+\mathrm{ve}$ \\
\hline
\end{tabular}

Instrument five: Quality of Partnership Likert Scale:

It was adopted from Michael Sheppard (2001) and modified by the researcher to assess the quality of partnership; it was divided into 4 parts. $(\mathrm{a}=.950)$.

1. Part one: Participation in decision making. It included 6 items. They were I always take part fully in all decisions made, some decisions were made without having taken part in the decision-making process, I was satisfied with the part I took in making decisions, etc .

2. Part two: Involvement in decisions implementation.it included 6 items. They were I have always taken an active part in sorting things out, I have sometimes taken an active part in sorting things out, I was satisfied with my involvement in sorting things out, etc.

3. Part three: Consultation. It included 6 items. They were the researcher always discussed all the important issues with me before decisions, the researcher discussed some of the important issues with me before decisions were made, I was satisfied with the amount of discussion with the researcher before decisions were made, etc.

4. Part four: Recipient of information. It included 6 items. They were the researcher always kept me informed on what was happening including their own action, I was satisfied with information provided by the researcher, etc.

Total scoring for Quality of Partnership:

\begin{tabular}{|l|l|}
\hline Scoring items & Score \\
\hline Low quality & $(<=50 \%)$ \\
\hline High quality & $(>50 \%)$ \\
\hline
\end{tabular}

For validity assurance, all instruments were submitted to a jury of five experts in the pediatric field (one professor in Pediatric Nursing, two assistant professors in Pediatric Nursing and two professors in Pediatric Medicine) to be sure for questionnaire items. Content validity was assessed using the scale content index average (S-CVI/ AVE) the lower limit of acceptability for SCVI/AVE was 0.80

\section{Ethical considerations}

A verbal acceptance was attained from the primary caregivers before including in the study. This consent was attained after explaining the aim and nature of the study. The study was harmless, voluntary and confidentiality of response would be respected. All caregivers had the full rights to refuse to have their children to includes in the study and withdraw at any time.

After the tool were developed and before starting the data collection, a pilot study was carried out on $10 \%$ of the total 
sample (six caregivers) to test the applicability, consistency, practicability, clarity and the feasibility of the study tools and to estimate the needed time to fill the tool. The necessary modification was done.

\section{Procedure}

1. Meetings were conducted with the directors of the elected settings to obtain permission to conduct the research explaining the purpose and expected outcomes. After that, an official permission to conduct the study was taken from the directors of the selected settings after submitting an official letter for the Dean of the Faculty of Nursing at Menoufia University explaining the purpose of the study and methods of data collection.

2. During pre-operative period, the researcher introduced herself to the caregivers who shared in the study and explained the purpose of the study and method of data collection

3. Goals of the program which were set by the researcher were shared with primary caregivers to determine areas of differences as well as unify health education goals

4. Data was collected about characteristics of children and their caregivers using instrument one. Then, assessment of caregiver's knowledge about the stoma was done (pretest) using instrument two also, Caregivers practice was assessed by observing their care while doing stoma care on a doll with stoma opening for both study and control group by using instrument three (pretest).

5. Collected data was used to analyze and determine areas of weakness in knowledge and practice of caregivers and for health education and family support .

6. The partnership program was constructed in order to overcome the gap of caregiver's knowledge and practice deficits as well as their satisfaction from shared partnership. It was designed in English language and translated into Arabic. It was designed to be provided into three sessions for three consecutive days /week during the morning shift. Health education was provided individually to each caregiver .

7. First session, the researcher started to work by creating welcoming atmosphere in order to let the caregivers feel valued as an expert on their own child. It contained theoretical information about the partnership program. Also, provide knowledge about the stoma, stoma care and discharge plan of children with stoma. This session lasted for two hour.

8. Second session was about caregivers practice regarding stoma care. Demonstration and remonstration were done for stoma care; it was done for each caregiver individually. This session lasted for 2 hour (practical part).

9. Third session was about debriefing caregiver's knowledge and practice to see to what extend they understood and mastery the skill, time allowed for each caregiver to ask question and feedback given. This session lasted for 1 hour.

10. A posttest was immediately done to assess knowledge and practice of primary caregivers using instrument two, three for both study and control group.

11. The researcher telephoned caregivers of each child one time per week. Necessary guidance and health education were provided according to the condition of each child and parents need. Researcher provides them psychological support and frequent telephone calls were needed to ensure their adherence to the program and helping them to solve their children accompanying problems as well as discuss their concerns. 
12. Follow up test was done after 4 weeks for both groups using all instruments.

\section{Statistical analysis:}

Data was coded and transformed into specially designed form to be suitable for computer entry process. Data was entered and analyzed by using SPSS (Statistical Package for Social Science) statistical package version 20. Graphics were done using Excel program.

Regarding quantitative data, were expressed inform of mean and standard deviation $(\mathrm{X} \pm \mathrm{SD})$ paired t-test was used for comparison of the same group on pre and post-test. Qualitative data was expressed in form of number and percentage, chi-square test $\left(\mathrm{X}^{2}\right)$ was used. For comparison between the quantitative data at different intervals for the same group, ANOVA test was used. Pearson correlation was also used for explaining relationship between normally distributed quantitative variable.

\section{Results}

Table 1 showed that about one third of studied children in the study group $(33.3 \%)$ were in the age group of 1 12 month. While, in the control group $33.3 \%$ were in the age group of 3- > 5years. Regarding children's gender, more than two thirds of studied children in both study and control group were boys. In relation to developmental stages, approximately one third (33.3\%) were in the infant stage in the study group; While in the control group about one third (33.3\%) were in the preschool stage. No statistical significant differences were found at $5 \%$ level of statistical significance between the two groups regarding the children's characteristics.

Table (1) Demographic Characteristics of the Studied Children in the study and control group.

\begin{tabular}{|c|c|c|c|c|c|c|}
\hline \multirow{2}{*}{ Characteristics } & \multicolumn{2}{|c|}{ Study } & \multicolumn{2}{|c|}{ Control } & \multirow{2}{*}{$\chi^{2}$} & \multirow{2}{*}{$\mathrm{P}$-value } \\
\hline & $\mathrm{No}=30$ & $\% 100$ & $\mathrm{No}=30$ & $\% 100$ & & \\
\hline $\begin{array}{l}\text { Child age } \\
\text { Birth- one month. } \\
1-12 \text { month. } \\
\text { 12month.->3 years } \\
3->5 \text { years } \\
5-10 \text { years }\end{array}$ & $\begin{array}{c}6 \\
10 \\
6 \\
4 \\
4\end{array}$ & $\begin{array}{l}20.0 \% \\
33.3 \% \\
20.0 \% \\
13.3 \% \\
13 . .3 \%\end{array}$ & $\begin{array}{c}6 \\
6 \\
3 \\
10 \\
5\end{array}$ & $\begin{array}{l}20.0 \% \\
20.0 \% \\
10.0 \% \\
33.3 \% \\
16.7 \%\end{array}$ & $5.82 \mathrm{~ns}$ & .121 \\
\hline $\begin{array}{r}\text { Child gender } \\
\text { Boy } \\
\text { Girl } \\
\end{array}$ & $\begin{array}{c}21 \\
9 \\
\end{array}$ & $\begin{array}{l}70.0 \% \\
30.0 \% \\
\end{array}$ & $\begin{array}{l}20 \\
10 \\
\end{array}$ & $\begin{array}{l}66.7 \% \\
33.3 \% \\
\end{array}$ & $.077 \mathrm{~ns}$ & .781 \\
\hline $\begin{array}{c}\text { Developmental stages } \\
\text { Neonate } \\
\text { Infant stage } \\
\text { Toddler stage } \\
\text { Preschool stage } \\
\text { School stage }\end{array}$ & $\begin{array}{c}6 \\
10 \\
6 \\
4 \\
4\end{array}$ & $\begin{array}{l}20.0 \% \\
33.3 \% \\
20.0 \% \\
13.3 \% \\
13.3 \% \\
\end{array}$ & $\begin{array}{c}6 \\
6 \\
3 \\
10 \\
5\end{array}$ & $\begin{array}{l}20.0 \% \\
20.0 \% \\
10.0 \% \\
33.3 \% \\
16.7 \%\end{array}$ & $4.68 \mathrm{~ns}$ & .321 \\
\hline $\begin{array}{c}\text { Number of sibling } \\
\text { One } \\
\text { Two } \\
\text { Three } \\
\text { More than } 3 \\
\end{array}$ & $\begin{array}{c}16 \\
6 \\
7 \\
1 \\
\end{array}$ & $\begin{array}{c}53.3 \% \\
20.0 \% \\
23.3 \% \\
3.3 \% \\
\end{array}$ & $\begin{array}{c}9 \\
14 \\
3 \\
4 \\
\end{array}$ & $\begin{array}{l}30.0 \% \\
46.7 \% \\
10.0 \% \\
13.3 \% \\
\end{array}$ & $8.56 \mathrm{~ns}$ & .036 \\
\hline $\begin{array}{l}\text { Birth orders } \\
\qquad \begin{array}{r}\text { First } \\
\text { Second } \\
\text { Thread } \\
\text { Fourth } \\
\text { Fifth }\end{array}\end{array}$ & $\begin{array}{c}11 \\
11 \\
4 \\
3 \\
1\end{array}$ & $\begin{array}{c}36.7 \% \\
36.7 \% \\
13.3 \% \\
10.0 \% \\
3.3 \%\end{array}$ & $\begin{array}{l}20 \\
5 \\
5 \\
0 \\
0\end{array}$ & $\begin{array}{l}66.7 \% \\
16.7 \% \\
16.7 \% \\
0.0 \% \\
0.0 \%\end{array}$ & $10.99 \mathrm{~ns}$ & .052 \\
\hline
\end{tabular}




\section{Effect of Partnership Based Program with Primary Caregivers of Children on \\ Stoma Care}

ns $\mathrm{p}>0.05 . \quad \chi 2$ : Chi square

Table 2 showed demographic characteristics of the caregivers in the study and control groups. Illustrated that the majority of caregivers in both study and control groups were mothers (90.0\% \& $93.3 \%$ respectively). Concerning the age of the parents, the results cleared that more than one third of studied parents were in the age group of 30-34years in both study and control group. In relation to father's and mother's education, more than half of parents in both study and control groups had middle education $(53.3 \%$ \&.50.0\% respectively). However, there were no statistical significant differences between characteristics of the caregivers in the two groups a 5\% level of statistical significance.

Table (2): Demographic Characteristics of the Caregivers in the Study and Control Groups.

\begin{tabular}{|c|c|c|c|c|c|c|}
\hline \multirow{2}{*}{ Characteristics } & \multicolumn{2}{|c|}{ Study } & \multicolumn{2}{|c|}{ Control } & \multirow{2}{*}{$\chi^{2}$} & \multirow{2}{*}{$P$-value } \\
\hline & No 30 & $\% 100$ & No 30 & $\% 100$ & & \\
\hline $\begin{array}{l}\text { Participant } \\
\text { Mother } \\
\text { Father }\end{array}$ & $\begin{array}{c}27 \\
3\end{array}$ & $\begin{array}{l}90.0 \% \\
10.0 \%\end{array}$ & $\begin{array}{c}28 \\
2\end{array}$ & $\begin{array}{c}93.3 \% \\
6.7 \%\end{array}$ & $.218^{\mathrm{ns}}$ & .640 \\
\hline $\begin{array}{l}\text { Age of parent } \\
20-24 y \\
25-29 y \\
30-34 y \\
35 y-\text { or more }\end{array}$ & $\begin{array}{c}5 \\
10 \\
11 \\
4\end{array}$ & $\begin{array}{l}16.7 \% \\
33.3 \% \\
36.7 \% \\
13.3 \%\end{array}$ & $\begin{array}{c}5 \\
8 \\
12 \\
5\end{array}$ & $\begin{array}{l}16.7 \% \\
26.7 \% \\
40.0 \% \\
16.7 \%\end{array}$ & $.377^{\mathrm{ns}}$ & .945 \\
\hline $\begin{array}{l}\text { Mothers work } \\
\text { Housewife } \\
\text { Worker } \\
\text { Employee }\end{array}$ & $\begin{array}{c}20 \\
4 \\
6\end{array}$ & $\begin{array}{l}66.7 \% \\
13.3 \% \\
20.0 \%\end{array}$ & $\begin{array}{c}20 \\
3 \\
7\end{array}$ & $\begin{array}{l}66.7 \% \\
10.0 \% \\
23.3 \%\end{array}$ & $.220^{\mathrm{ns}}$ & .896 \\
\hline $\begin{array}{l}\text { Level of education } \\
\text { Illiterate } \\
\text { Primary education } \\
\text { Secondary education } \\
\text { Middle education } \\
\text { High education }\end{array}$ & $\begin{array}{c}1 \\
0 \\
2 \\
16 \\
11\end{array}$ & $\begin{array}{c}3.3 \% \\
0.0 \% \\
6.7 \% \\
53.3 \% \\
36.7 \%\end{array}$ & $\begin{array}{c}0 \\
1 \\
4 \\
14 \\
11\end{array}$ & $\begin{array}{c}0.0 \% \\
3.3 \% \\
13.3 \% \\
46.7 \% \\
36.7 \%\end{array}$ & $2.80^{\mathrm{ns}}$ & .592 \\
\hline $\begin{array}{l}\text { Level of father education } \\
\text { Illiterate } \\
\text { Read and write } \\
\text { Secondary education } \\
\text { Middle education } \\
\text { High education }\end{array}$ & $\begin{array}{c}2 \\
2 \\
3 \\
14 \\
9\end{array}$ & $\begin{array}{c}6.7 \% \\
6.7 \% \\
10.0 \% \\
46.7 \% \\
30.0 \%\end{array}$ & $\begin{array}{c}0 \\
2 \\
3 \\
15 \\
10\end{array}$ & $\begin{array}{c}0.0 \% \\
6.7 \% \\
10.0 \% \\
50.0 \% \\
33.3 \%\end{array}$ & $2.08^{\mathrm{ns}}$ & .720 \\
\hline $\begin{array}{l}\text { Father work } \\
\text { Not working } \\
\text { Worker } \\
\text { Employee }\end{array}$ & $\begin{array}{c}4 \\
11 \\
15\end{array}$ & $\begin{array}{l}13.3 \% \\
36.7 \% \\
50.0 \%\end{array}$ & $\begin{array}{c}4 \\
13 \\
13\end{array}$ & $\begin{array}{l}13.3 \% \\
43.3 \% \\
43.3 \%\end{array}$ & $.310^{\mathrm{ns}}$ & .857 \\
\hline $\begin{array}{l}\text { Economic level } \\
\text { NOT enough } \\
\text { Enough }\end{array}$ & $\begin{array}{l}15 \\
15\end{array}$ & $\begin{array}{l}50.0 \% \\
50.0 \%\end{array}$ & $\begin{array}{l}15 \\
15\end{array}$ & $\begin{array}{l}50.0 \% \\
50.0 \%\end{array}$ & $.000^{\mathrm{ns}}$ & 1.000 \\
\hline
\end{tabular}

NB: ns p> 0.05. $\quad \chi^{2}$ : Chi square

Table $\mathbf{3}$ demonstrated distribution of children in the study and control groups 
according to their present medical history. The table represented that more than one third $(36.7 \%)$ of children were diagnosed with intestinal obstruction. while, children who had Hirshsprunge, Congenital colon anomalies and
Imperforated Anus were $(33.3 \% 16.7 \%$, $\& 16.7 \%$ respectively). Concerning the site of stoma, the majority of children in the study and control groups had colon stoma $(83.3 \%$ \& $93.3 \%$ respectively).

Table (3) Distribution of Children in the Study and Control Groups According to Their Present Medical History.

\begin{tabular}{|c|c|c|c|c|c|c|}
\hline \multirow{2}{*}{ Present Medical History } & \multicolumn{2}{|c|}{ Study } & \multicolumn{2}{|c|}{ Control } & \multirow{2}{*}{$\chi^{2}$} & \multirow{2}{*}{$P$-value } \\
\hline & No $=30$ & $\overline{~ \% ~}$ & $\mathrm{No}=30$ & $\%$ & & \\
\hline \multirow{2}{*}{$\begin{array}{l}\text { Time of beginning complain } \\
>6 \mathrm{~m} \\
<6 \mathrm{~m}\end{array}$} & & & & & & \\
\hline & $\begin{array}{l}20 \\
10\end{array}$ & $\begin{array}{c}66.7 \\
33.3 \%\end{array}$ & $\begin{array}{c}25 \\
5\end{array}$ & $\begin{array}{c}83.3 \% \% \\
16.7 \%\end{array}$ & 2.22 & .136 \\
\hline $\begin{array}{l}\text { Reasons for doing operation } \\
\text { Congenital colon anomalies } \\
\text { Cancer colon } \\
\text { Intestinal obstruction } \\
\text { Imperforated anus } \\
\text { Hirshsprunge } \\
\text { Cohn's disease }\end{array}$ & $\begin{array}{c}5 \\
1 \\
9 \\
3 \\
10 \\
2\end{array}$ & $\begin{array}{c}16.7 \% \\
3.3 \% \\
30.0 \\
10.0 \\
33.3 \% \\
6.7 \%\end{array}$ & $\begin{array}{c}2 \\
0 \\
11 \\
5 \\
10 \\
2\end{array}$ & $\begin{array}{c}6.7 \% \\
0.0 \% \\
36.7 \% \% \\
16.7 \% \% \\
33.3 \% \\
6.7 \%\end{array}$ & $2.98^{\text {ns }}$ & .702 \\
\hline $\begin{array}{l}\text { Types of Stoma:- } \\
\text { Temporary } \\
\text { Permanent }\end{array}$ & $\begin{array}{c}26 \\
4\end{array}$ & $\begin{array}{l}86.7 \% \\
13.3 \%\end{array}$ & $\begin{array}{c}26 \\
4\end{array}$ & $\begin{array}{l}86.7 \% \\
13.3 \%\end{array}$ & .00 & 1.000 \\
\hline $\begin{array}{l}\text { Site of Stoma } \\
\text { Colon } \\
\text { Ileum }\end{array}$ & $\begin{array}{c}25 \\
5\end{array}$ & $\begin{array}{l}83.3 \% \\
16.7 \%\end{array}$ & $\begin{array}{c}28 \\
2\end{array}$ & $\begin{array}{c}93.3 \% \\
6.7 \%\end{array}$ & 1.456 & .228 \\
\hline $\begin{array}{l}\text { Problems from stoma } \\
\text { Constipation } \\
\text { Diarrhea } \\
\text { Distention } \\
\text { Offensive odor } \\
\text { Others }\end{array}$ & $\begin{array}{c}4 \\
5 \\
7 \\
11 \\
3\end{array}$ & $\begin{array}{l}14.3 \% \\
17.9 \% \\
25.0 \% \\
36.7 \% \\
10.7 \%\end{array}$ & $\begin{array}{c}0 \\
2 \\
7 \\
13 \\
8\end{array}$ & $\begin{array}{c}0.0 \% \\
6.7 \% \\
23.3 \% \\
43.3 \% \\
26.7 \%\end{array}$ & $8.22^{\mathrm{ns}}$ & .084 \\
\hline
\end{tabular}

NB: ns p> 0.05. $\chi^{2}$ : Chi square

Table 4 showed mean total scores of caregiver knowledge regarding stoma on pre, post and follow-up test. It was obvious that the mean total score of caregiver's knowledge in the study group on pre, post and follow up test were 14.63

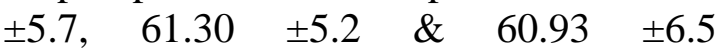
respectively. Therefore, there were highly statistical significant differences at $1 \%$ level of statistical significant in the study group between pre, post and follow up test. .Meanwhile, in the control group the mean total score of caregiver's knowledge on pre, post and follow up test were 13.33 $\pm 4.9,14.63 \pm 5.7 \& 18.40 \pm 8.2$ respectively. Therefore, there were statistical significant differences at $5 \%$ level of statistical significant in the control group between pre, post and follow up test

Table (4): Mean Total Scores of Caregivers Knowledge Regarding Stoma on Pre, Post and Follow-up Test in the Study and Control Group. 


\section{Effect of Partnership Based Program with Primary Caregivers of Children on Stoma Care}

\begin{tabular}{|l|c|c||c||c|c||}
\hline Mean Total Score & $\begin{array}{c}\text { Pretest } \\
\text { Mean } \pm \text { SD }\end{array}$ & $\begin{array}{c}\text { Post-test } \\
\text { Mean } \pm \text { SD }\end{array}$ & $\begin{array}{c}\text { Follow-up } \\
\text { Mean } \pm \text { SD }\end{array}$ & Anova test & p-value \\
\hline \hline Study group & $14.63 \pm 5.7$ & $61.30 \pm 5.2$ & $60.93 \pm 6.5$ & $509.025^{* *}$ & .000 \\
\hline \hline Control group & $13.33 \pm 4.9$ & $14.63 \pm 5.7$ & $18.40 \pm 8.2$ & $4.542^{*}$ & .013 \\
\hline
\end{tabular}

NB: $\quad(*)=$ significant $(\mathrm{p}<0.05) \quad(* *)=(\mathrm{p}<0.001)$

Table 5 indicated mean of total practice scores regarding stoma care on pre, post and follow-up test. The table illustrated that caregivers had higher mean score of performance posttest in the study group compared to control respectively). Moreover, there were highly statistical significant differences between caregivers' practices in the study group pre, post and follow-up test at $1 \%$ level of statistical significance

group $(28.33 \pm 1.01 \mathrm{vs} .4 .06 \pm 2.5$

Table (5): Mean of Total Practice Scores Regarding Stoma Care in the Study and Control Groups on Pre, Post and Follow-up Test.

\begin{tabular}{|c|c|c|c|c|c|}
\hline \multirow[b]{2}{*}{ Items } & \multicolumn{3}{|c|}{ Mean Total Scores } & \multirow[b]{2}{*}{ Anova test } & \multirow{2}{*}{$\begin{array}{c}\text { P- } \\
\text { value }\end{array}$} \\
\hline & $\begin{array}{c}\text { Pretest } \\
\text { Mean } \pm \text { SD }\end{array}$ & $\begin{array}{c}\text { Post-test } \\
\text { Mean } \pm \text { SD }\end{array}$ & $\begin{array}{c}\text { Follow-up } \\
\text { Mean } \pm \text { SD }\end{array}$ & & \\
\hline Study group & $1.67 \pm 1.03$ & $28.33 \pm 1.01$ & $27.3 \pm 1.8$ & $139.6(* *)$ & .000 \\
\hline Control group & $0.167 \pm 0.46$ & $4.06 \pm 2.5$ & $5.06 \pm 4.18$ & $4.373(*)$ & (.043 \\
\hline
\end{tabular}

NB: Note: $(*)=(p<0.05)$

$(* *)=(\mathrm{p}<0.001)$

Figure 1 reflected Pearson correlation between total caregivers' knowledge and practices regarding stoma care. This figure clarified that there were positive highly statistical significance

correlation between total caregivers knowledge and practices regarding stoma care at $1 \%$ level of statistical significance.

\section{Figure (1) Pearson Correlation between Total Caregivers' Knowledge and Practice Regarding Stoma Care.}

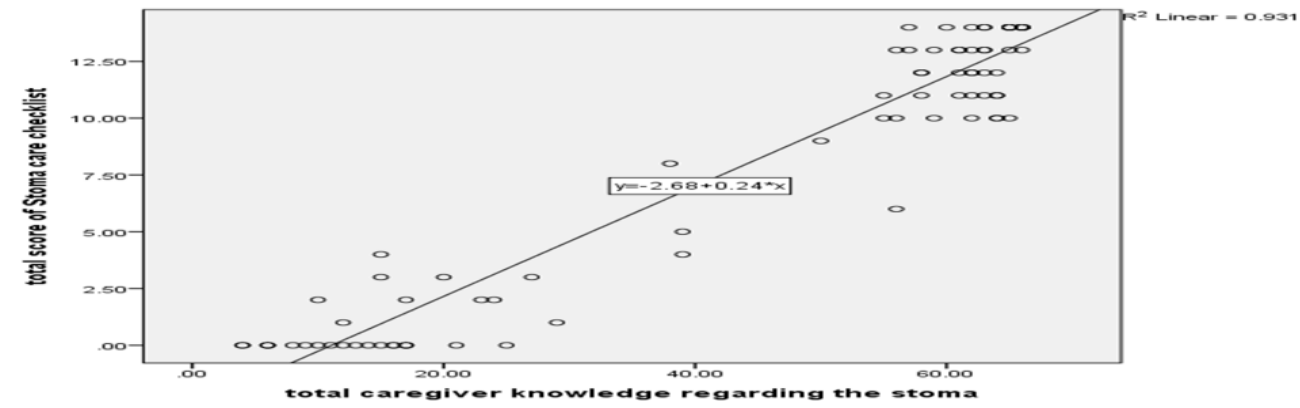

Figure 2 described stoma Swab (Culture Sensitivity Test) in the study and control groups on post and followup test (first and second measurement). The results revealed that more than half of children in the study group had no growth of microorganisms on followup test (second measure) compared to control group $(70.0 \%$ vs. $6.7 \&$ respectively). Regarding presence of gram negative bacilli (ECOLI), it was obvious that only $16.7 \%$ of children had the gram negative bacilli in the study group on follow-up test (second measure) while, $33.3 \%$ of children in the control group had the gram negative bacilli . On the other hand, gram negative bacilli (kelbcella) was absent in the study group on follow-up test (second measure) compared to 
control group $(0.0 \%$ vs. $16.7 \% \quad$ in the follow-up test (second measure) respectively). Therefore, there were at $1 \%$ level of statistical significance. statistical significant differences between the study and control groups

Figure (2): Stoma Swab (Culture Sensitivity Test) in the Study and Control Groups on Post and Follow-up Test.

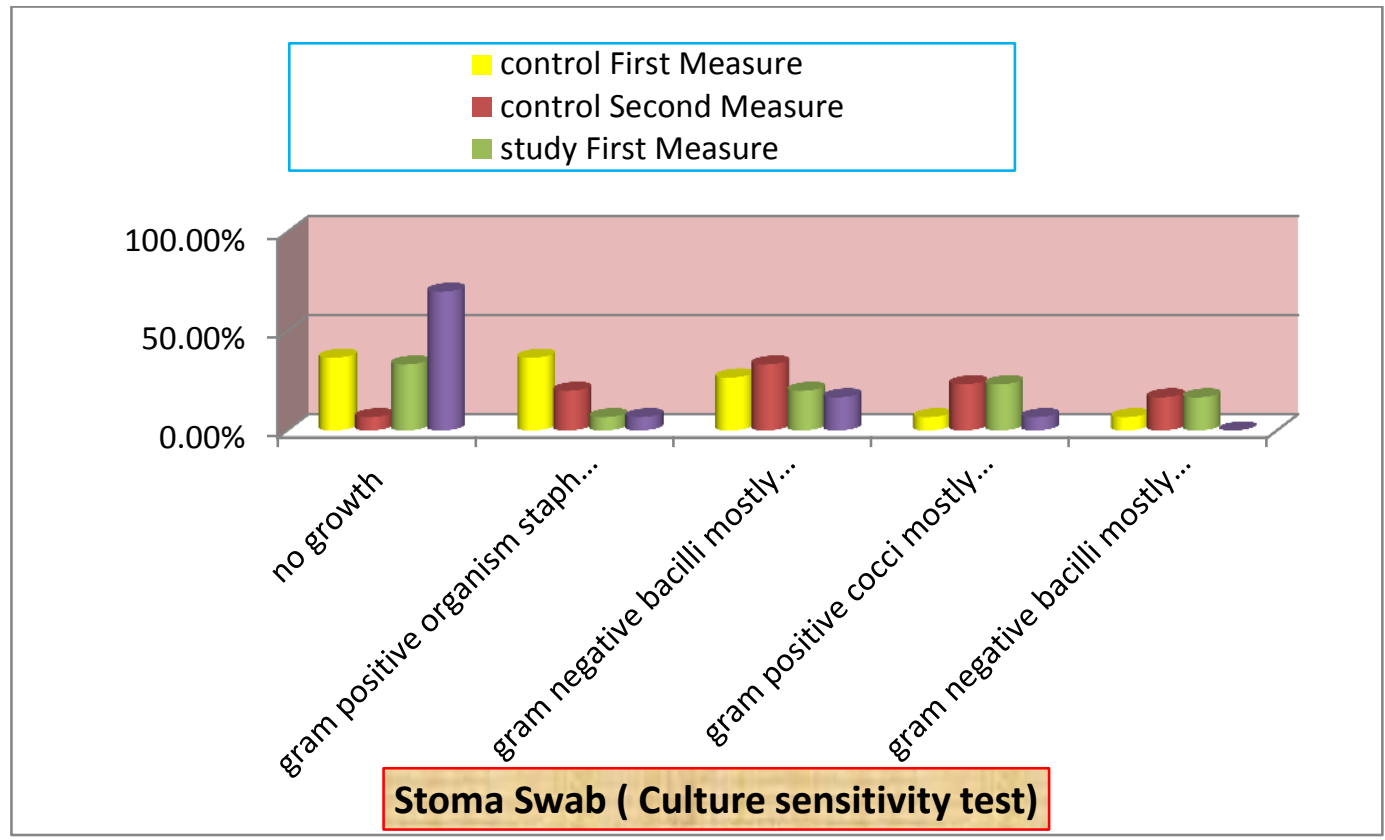

Table 6 represented mean scores for quality of partnership in the study group on pre, post and follow-up test. It was obvious that, the mean total score and standard deviation of partnership quality on posttest in the study group were $22.50 \pm 3.1$ compared to $4.67 \pm 4.6$ in pretest. Also, the table revealed that parents had high level of quality posttest than pretest. For this reason, there were highly statistical significant differences between caregivers in the study group at $1 \%$ level of statistical significance.

Table (6): Mean Scores for Quality of Partnership in the Study Group on Pre, Post and Follow-up Test.

\begin{tabular}{|c|c|c|c|c|c|}
\hline \multirow[b]{2}{*}{ Items } & \multicolumn{3}{|c|}{ Mean Total scores } & \multirow[b]{2}{*}{ Anova test } & \multirow[b]{2}{*}{ p-value } \\
\hline & $\begin{array}{c}\text { Pretest } \\
\text { Mean } \pm S D\end{array}$ & $\begin{array}{c}\text { Post-test } \\
\text { Mean } \pm \text { SD }\end{array}$ & $\begin{array}{l}\text { Follow-up } \\
\text { Mean } \pm S D\end{array}$ & & \\
\hline Study group & $4.67 \pm 4.6$ & $22.50 \pm 3.1$ & $21.67 \pm 2.4$ & $253.98^{(* *)}$ & .000 \\
\hline
\end{tabular}

Table 7 displayed mean total scores for caregiver's satisfaction in the study group on pre, post and follow-up test. It was clear that the mean total score and standard deviation of caregivers satisfaction on posttest in the study

group were $7.60 \pm 1.04$ compared to $1.33 \pm 1.52$ in pretest. For this reason, there were highly statistical significant differences between caregivers in the study group at $1 \%$ level of statistical significance

Table (7): Mean Total Scores for Caregiver's Satisfaction in the Study Group on Pre, Post and Follow-up Test. 


\section{Effect of Partnership Based Program with Primary Caregivers of Children on Stoma Care}

\begin{tabular}{|c|c|c|c|c|c|}
\hline \multirow[b]{2}{*}{ Items } & \multicolumn{3}{|c|}{ Mean Total Scores } & \multirow[b]{2}{*}{ Anova test } & \multirow[b]{2}{*}{ p-value } \\
\hline & $\begin{array}{c}\text { Pretest } \\
\text { Mean } \pm S D\end{array}$ & $\begin{array}{c}\text { Post-test } \\
\text { Mean } \pm S D\end{array}$ & $\begin{array}{l}\text { Follow-up } \\
\text { Mean } \pm S D\end{array}$ & & \\
\hline$\overline{~ S t u d y ~ g r o u p ~}$ & $101.33 \pm 1.52$ & 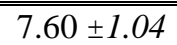 & 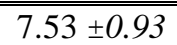 & $274.11^{(H S)}$ & $\overline{2.000}$ \\
\hline
\end{tabular}

\section{DISCUSSION}

The care of a child with colostomy is a complex, challenging and lengthy process, despite its temporary status in most children. After stoma formation, stoma care has to be provided to the child by caregivers at home. Hence, caregivers need to be provided with ongoing education and support commencing from preoperative teaching to discharge from the hospital and home care (Kalia et al, 2016). Therefore, our main target is to support the family to provide care for their children and to assess the effect of partnership with primary caregiver on their care for child having stoma

The current study hypothesized that primary caregivers who received partnership based program would gain more knowledge and practices related to stoma care. Also; their children would have better clinical condition of their stoma.

Regarding characteristics of studied children, this study illustrated that about one third of them aged between 1-12 months. This study is supported by Bagi et al, (2016) who conducted a study about "Management care for children with stoma"; their study revealed that a stoma was most common in children who range between 1-48 months. This could be attributed to the necessity for the early management of children having congenital anomalies such as (HD, Imperforated Anus and Intestinal obstruction).

Concerning children's gender, the current study revealed that more than two thirds of studied children in both study and control group were boys and one third were girls. This result goes in the same line with Zaki (2016) and MacKeigan \& Cataldo (2017) they revealed that congenital GIT anomalies are more common in male than female. This was attributed to the prevalence of congenital and genetic disorders in infants and young children between males than females (4:1) worldwide.

Regarding characteristics of the caregivers, the findings of the present study revealed that the majority of caregivers in both study and control groups were mothers. This result was in agreement with Kadam and Shinde (2017) they stated in a study about "Effectiveness of structured education on caregiver's knowledge and attitude regarding colostomy care", that $33.33 \%$ of primary caregivers were males and $66.67 \%$ were females. Northfield \& Nebauer (2019) who founded in a study about "The caregiving journey for family members of relatives with cancer", that mother were the traditional caregivers for children in Western society, In Egypt; mothers were also the most common primary caregivers of children because fathers are believed to take more responsibility in financial matters.

Concerning present medical history for the child, the current study reflected that the most prevalent indications for stoma were HD and imperforated anus (one third in study and control groups). This finding was consistent with Dabas, et al, (2016) and Ameh, et al, (2018) their study reported that indication for stoma in children who had undergone temporary colostomy were $\mathrm{HD}$ and anorectal malformations.

Regarding mean total scores of caregiver knowledge about stoma on pre, post and follow-up phases. This study showed that caregivers had higher mean total knowledge score post intervention than 
pre intervention. Such finding was agreed with Zaki et al, (2016) who found that mothers had higher total mean scores of knowledge on post than pre, test. From the researcher's point of view such findings could be attributed to the good relationship which were developed between the researcher and caregivers which in turn was reflected in fulfilling the needs of caregivers for knowledge about stoma care and providing the missing and needed items.

Concerning mean of total practice scores regarding stoma care in the study and control groups on pre, post and follow-up test, this study showed that caregivers had higher mean score of performance post intervention in the study group compared to control group. Such finding was supported by Culha et al., (2016) who stated that mean scores mothers practices related to care of their children with stoma improved after program implementation. From the researcher's opinion, this could be due to successfulness of shared session which encouraged caregiver's to provide their best performance after having practice session and the good interpersonal relationship between the researcher and caregivers. Thereby, the researcher was able to satisfy the caregiver's missing needs.

It was clear that there were positive correlation between total caregiver's knowledge and practices regarding stoma care. This result was in line with Hegazy, et al., (2015) who conducted a study about "Outcomes of Educational Guidelines on Awareness and SelfEfficacy among Patients with Permanent Colostomy?" This could assure that improvement of maternal care would be due to improvement of knowledge.

Regarding stoma Swab, (Culture Sensitivity Test), the results revealed that more than half of children in the study group had no growth of microorganisms four weeks following surgery compared to control group. The improvement after intervention could be due to proper caregiver's practices and the provision of stoma pouches by the researcher to mother in order to provide proper stoma care.

Regarding mean scores of partnership quality in the study group on pre, post and follow-up test. The study revealed that parents had higher level of quality on posttest than pretest. This finding was supported with Vasli and Salsali (2018) who conducted a study about "Parents' participation in taking care of hospitalized children: A concept analysis with hybrid mode". The study concluded that encouraging parents to participate in taking care of a hospitalized child increased quality of care. From the researcher's perspective, this could be due to the mutual relationship and the researcher's gaining parents' trust, giving the required information and education to the parents about care and treatment process, assigning the needed home care to the parents, involving the parents in caregiving process improved the quality of care given to the children.

Moreover, this finding came in line with Owen, et al., (2019) they conducted a study about "Caregiver-mother partnership behavior and the quality of caregiver-child and mother-child interactions". Their study reported that mothers who engaged in more partnership behavior with nurses were more supportive and sensitive with their children. Therefore, parents should be encouraged to be active partners in decision-making process.

Concerning involvement in decisions implementation, the present study reflected that most of the caregivers were involved in decision implementation on posttest than pretest. This result came in line with Coyne and Cowley (2017) their study reported that parents felt compelled to be available during care that was provided by nurses and responsible for their children's welfare in the hospital. The mother took an active part in 
resolving any child health problem and they did something rather than relied exclusively upon the actions of others. From the researcher's perspective, this could be attributed to the partnership program that helped caregivers to build skills to manage their children's illness.

Furthermore, this result was consistent with Sinclair and Grimshaw (2018) who conducted a study about "Partnership with parents in planning the care of their children". The study showed that Parents can only be more equal partners when they have the knowledge they need to understand the planning process and their role in it.

Concerning satisfaction of caregivers regarding quality of partnership, it was cleared that most of the caregivers were more satisfied in the study group on posttest than pretest. Such finding was supported with Reis, et al., (2015) in a study about "Developing nurse/parent relationships in the NICU through negotiated partnership". The study concluded that developing a collaborative and effective nurse/parent relationship is the most significant factor affecting parents' satisfaction with their experience.

\section{CONCLUSION}

Based on the finding of the present study and hypothesis, it was concluded that: Primary caregivers who received partnership based program had higher level of knowledge and demonstrated higher level of stoma care than primary caregivers who received only routine hospital care. Also, their children had better clinical condition of their stoma than those who received only routine hospital care.

\section{Recommendations}

Based on the findings of the present study, the following recommendations can be suggested:

1. Nurses in pediatric
department surgical
should partnership with the primary caregivers.

2. Partnership in-service education programs should encourage nurses to develop personal communication and relationship with the caregivers.

3. Counseling room in the pediatric department should be established to provide children and their parents with the needed information to promote children health and referred them to appropriate places.

4. Policies of the pediatric surgical departments should optimize the concept of parental involvement in stoma care to improve children health status.

5. Future studies are needed to determine the effect of applying partnership program in different demographic areas

\section{References}

Abdou, M. S. M., Sherif, A. A. R., Wahdan, I. M. H., \& El din Ashour, K. S. (2019). Pattern and risk factors of congenital anomalies in a pediatric university hospital, Alexandria, Egypt. Journal of the Egyptian Public Health Association, 94(1), 3.

Alfandari, R. (2017). Evaluation of a national reform in the Israeli child protection practice designed to improve children's participation in decision-making. Child \& Family Social Work, 22, 54-62.

Ameh, E. A., Mshelbwala, P. M., Sabiu, L., \& Chirdan, L. B. (2016). Colostomy in children-an evaluation 


\section{Effect of Partnership Based Program with Primary Caregivers of Children on Stoma

of acceptance among mothers and caregivers in a developing country. South African Journal of Surgery, 44(4), 138-139.

American Academy of Pediatrics (AAP). (2018). Policy statement. Patientand family-centered care and the pediatrician's role. Pediatrics 129(2), 394- 404.

Bagi, P., Jendresen, M., \& Kirkegaard, P. (2016). Early local stoma complications in relation to the applied suture material: comparison between monofilament and multifilament sutures. Diseases of the colon \& rectum, 35(8), 739-742 Indian Assoc Pediatr Surg. 2016;9:15-9.

Barreire, S. G., Oliveira, O. A., Kazama, W., Kimura, M., \& Santos, V. L. (2016). Quality of life of children with stomas: the children and mothers' point of view. J Pediatr (Rio J), 79(1), 55-62.

Cengiz, B., \& Bahar, Z. (2017). Perceived barriers and home care needs when adapting to a fecal ostomy. Journal of Wound, Ostomy and Continence Nursing, 44(1), 63-68.

Coyne, I., \& Cowley, S. (2017). Challenging the philosophy of partnership with parents: a grounded theory study

Culha, I., Kosgeroglu, N., \& Bolluk, O. (2016). Effectiveness of self-care education on patients with stomas. IOSR Journal of Nursing and Health Science, 5(2), 70-76.

Dabas, H., Sharma, K. K., Joshi, P., \& Agarwala, S. (2016). Video teaching program on management of colostomy: Evaluation of its impact on caregivers. Journal of Indian Association of Pediatric Surgeons, 21(2), 54 .

Drugli, M. B., \& Undheim, A. M. (2017). Partnership between parents and caregivers of young children in fulltime daycare. Child care in practice, 18(1), 51-65.

Hegazy, S. M., Ali, Z. H., Mahmoud, A. S., \& Abou-Zeid, A. A. (2015). Outcomes of Educational Guidelines on Awareness and Self-Efficacy among Patients with Permanent Colostomy. New York Science Journal, 7(3), 25-32.

Heo, Y. J., \& Oh, W. O. (2019). The effectiveness of a parent participation improvement program for parents on partnership, attachment infant growth in a 
neonatal intensive care unit: A randomized controlled trial. International journal of nursing studies, 95, 19-27.

Kadam, A., \& Shinde, M. B. (2017). Effectiveness of structured education on caregiver's knowledge and attitude regarding colostomy care. International Journal of Science and Research (IJSR), 3(4), 586-593.

Kalia, R., Walia, I., \& Rao, K. L. N. (2016). Development of educational aids for the parents of children having colostomy. Journal of Indian Association of Pediatric Surgeons, 9(1), 15 .

Kuhlthau, K. A., Bloom, S., Van Cleave, J., Knapp, A. A., Romm, D., Klatka, K., ... Perrin, J. M. (2018). Evidence for family-centered care for children with special health care needs: A systematic review. Academic Pediatrics, 11(2), 136_143. doi:10.1016/j.acap. 2010.12.014

Lam, J., Spence, K., \& Halliday, R. (2017). Parents' perception of nursing support in the neonatal intensive care unit (NICU). Neonatal Pediatr

MacKeigan, J. M., \& Cataldo, P. A. (2017). Intestinal stomas: principles, techniques, and management. Informa Healthcare.

Maia, E. M. B., \& Assis, G. M. (2019). Perception of the parents of children with intestinal stoma regarding the nursing orientations. EstimaBrazilian Journal of Enterostomal Therapy, 17

Massenga, A., Chibwae, A., Nuri, A. A., Bugimbi, M., Munisi, Y. K., Mfinanga, R., \& Chalya, P. L. (2019). Indications for and complications of intestinal stomas in the children and adults at a tertiary care hospital in a resource-limited setting: a Tanzanian experience. BMC gastroenterology, 19(1), 157.

Mohamed, S. S., Salem, G. M., \& Mohamed, H. A. (2017). Effect of self-care management program on self-efficacy among patients with colostomy. American Journal of Nursing Research, 5(5), 191-9.

Northfield, S., \& Nebauer, M. (2019). The Caregiving Journey for Family Members of Relatives with Cancer. Clinical Journal of Oncology Nursing, 14(5).

Owen, M. T., Ware, A. M., \& Barfoot, B. (2019). Caregiver-mother partnership behavior and the quality 
of caregiver-child and mother-child interactions. Early Childhood Research Quarterly, 15(3), 413-428.

Reis, M. D., Rempel, G. R., Scott, S. D., Brady-Fryer, B. A., \& Van Aerde, J. (2015). Developing nurse/parent relationships in the NICU through negotiated partnership. Journal of Obstetric, Gynecologic \& Neonatal Nursing, 39(6), 675-683.

Sinclair, R., \& Grimshaw, R. (2018). Partnership with parents in planning the care of their children. Children \& society, 11(4), 231-241.

Smith, J., Swallow, V., \& Coyne, I. (2018). Involving parents in managing their child's long-term condition-A concept synthesis of family-centered care and partnership-in-care. Journal of pediatric nursing, 30(1), 143-159.

Sun, J., Luo, C., Jia, J., Suping, B. O., \& Wei, Q. (2018). Caring experiences of family caregivers of patients with enterostomy in different stages based on. Modern Clinical Nursing, 17(1), 33-38.

Thompson, N. M. (2019). Nursing Care and Management of Gastrostomy and Gastojejunostomy Tubes in the Pediatric Population. Journal of Pediatric Surgical Nursing, 8(4), 97111.

UNICEF. (2017). Levels and Trends in Child Mortality.. World Health Organization Avenue Appia 20, 1211 Geneva 27, Switzerland.

Vasli, P., \& Salsali, M. (2018). Parents' participation in taking care of hospitalized children: A concept analysis with hybrid model. Iranian journal of nursing and midwifery research, 19(2), 139.

World Health Organization. (2016). Cancer pain relief and palliative care in children. Geneva, Switzerland: Author.Google Scholar link 